\title{
Metagenomic analysis reveals rumen microbiota alteration of the yak at different stages of growth
}

\section{Li Wang ( $\nabla$ qinxin916@aliyun.com )}

Southwest Minzu University https://orcid.org/0000-0001-8267-9309

Li Juan

Southwestern University

Ahmad Aboragah

University of Illinois at Chicago

Mingfeng Jiang

Southwest Minzu University

Juan J. Loor

University of Illinois at Chicago

\section{Research Article}

Keywords: Microbiome, Metagenomics, Morphology, Rumen, Yak

Posted Date: July 9th, 2021

DOl: https://doi.org/10.21203/rs.3.rs-683476/v1

License: (c) (1) This work is licensed under a Creative Commons Attribution 4.0 International License. Read Full License 


\section{Abstract}

The Yak (Bos grunniens) is a unique ruminant species that is crucially important to agriculture in the Tibetan plateau. Variation of microorganism communities in the yak rumen is of great interest because of possible links to environmentally and economically important traits. In this study, we performed histological and microbial analyses of the yak rumen at 5 stages of growth: 1 day, 20 days, 60 days, 15 months, and 5 years of age. Tissue slices and metagenomics sequencing were used. The rumen index increased gradually from 1 day to 5 years of age. These were significant differences in rumen index between the $60 \mathrm{~d}, 15 \mathrm{~m}$, and $5 \mathrm{y}$ group $(p<0.05)$. Compared with other time points, the thickness of muscularis along with length and width of rumen papillae at $60 \mathrm{~d}, 15 \mathrm{~m}$, and 5 years of age increased and differed $(p<0.05)$, respectively. At the phylum level, Bacteroidetes and Firmicutes were the phyla with the highest abundance in all the age groups. A total of 115,401 genes were annotated on the CAZy database. Glycoside Hydrolase (GH) had the highest relative abundance, followed by Glycosyl Transferase (GT), and Carbohydrate-binding Modules (CBM). There were significant variations for the microbial species and CAZys within the five groups. Taken together, the morphology and microbiota in the yak rumen changed at various stages of growth and likely played a significant role in the absorption of nutrients. This study provides new insights into the function of yak rumen microbiota and physiologic adaptations in plateau animals.

\section{Introduction}

Ruminant production is of great economic value and underpins food security in various parts of the world. The rumen contains a microbial ecosystem in which a dense and complex mixture of bacteria, protozoa, archaea, and fungi convert carbohydrates to short-chain and volatile fatty acids that can be used by the host. Rumen microbes allow the animal to transform plant forages, inedible for humans, into high-quality foods [1-2]. Numerous studies have investigated the symbiotic microorganisms in the rumen because of their link to feed conversion efficiency [3], economically or environmentally important traits such as methane production [4], and a more recent discovery of microbes and enzymes which enable fermentation of biomass for biofuel production [5].

To date, the structure and function of rumen microbial community have been studied in different host species, including cattle [6], sheep [7], beef cattle [8], buffalo [9], cattle-yak [10], and yak [11]. Despite the marvelous industrial and scientific interest, the rumen remains an under-characterized environment, including many microbial species and strains which have not been cultured. A better cognition of microbial composition and the function of microbes in fermentation is first required to manipulate the rumen microbiota.

The Yak is a unique ruminant species, a large member of the bovine family, which differentiated from other ruminant animals about a few million years ago [12]. The yak is the most important animal species in the Qinghai-Tibet Plateau (QTP), which is the most important terrestrial ecosystem in Eurasia, with altitudes ranging from 3,000 to 5, $000 \mathrm{~m}$ [13]. Yak farming is at the center of living conditions for the local 
farming community, and provides the most important food source. The yak rumen has a complex microbial community and plays a vital role in sustaining growth of the animal.

Studies such as the classical work of Baldwin and Connor described the basic structure and metabolic features of the epithelial lining of the bovine rumen. They discussed the importance of differentiation of the tissue during normal production practices [14]. There are few reports regarding the morphology and microbiota of the yak rumen [14-16]. For example, composition and individual variability of microbiota of the adult yak rumen were both investigated using $16 \mathrm{~S}$ rRNA sequencing $[17,18]$. The effect of feed type on the ruminal fluid microbiota and metabolites in yak was characterized by 16S rRNA gene sequencing and liquid chromatography-mass spectrometry (LC-MS) [11]. More recently, sequencing of the 16S rRNA gene also has been used to compare bacterial communities across different stages of forage growth, seasons, and between female and male yaks [16]. In addition, the cellulolytic microbiome of the mature yak rumen was analyzed using a combination of bacterial artificial chromosome (BAC)-based and metagenome-based functional screening approaches [19]. Despite the importance of factors that impact profiles of ruminal microbes including species, age, season, and especially diet [20], the identification and composition of the primary ruminal bacterial communities acquired promptly after birth in yak and the changes occurring in these communities at various growth stages of the animal remain largely unknown [21]. In that context, a combined evaluation of morphological and microbial changes during growth also would be valuable.

A better understanding of the ruminal microbiome and its underlying functions through the construction of a gene catalogue can inform strategies to improve feed digestion efficiency and reduce enteric methane production, thus, helping to meet sustainability challenges [1]. Thus, the present study mainly aimed to investigate changes in microbiota and morphology of the yak rumen at different growth stages. Data generated from this study can provide new knowledge of the physiologic adaptations in ruminants of the Tibetan plateau, and potentially help develop management strategies to improve their productivity.

\section{Materials And Methods}

\subsection{Animals and sample collection}

Animal experiments were conducted at the Hongyuan Yak Research Centre, Sichuan Province, China. A total of 15 female yaks ( $n=3$ at each stage) were selected at 1 day, 20 days, 60 days, 15 months, and 5 years of age. The 1 day sample represents birth, 20 days represents the time the yak calf begins to eat grass, 60 days represents the time the yak calf was mainly fed on grass, 15 months represents the stage the yak calf was fed on grass, 5 years representsa the dult yak fed on grass. Considering that long experimental periods would be associated with changes in forage quality and availability that may affect ruminal microbiota, all samples were collected between June to September, coinciding with the green grass season in the Tibetan plateau. These animals were raised at Hongyuan Yak Research Centre, Southwest Minzu University, and all experimental procedures were approved by the Animal Care and Use Committee of Southwest Minzu University, following the guidelines of the Sichuan Council on Animal 
Care (Ministry of Science and Technology, China, revised in June 2004). Yaks were euthanized by captive bolt and slaughtered at Hongyuan slaughterhouse. One-hundred $\mathrm{ml}$ of ruminal fluid was collected after slaughter. Samples were randomly collected from at least three different parts of the rumen and filtered through sterile gauze. Subsequently, the liquid was immediately frozen in liquid nitrogen and then stored at $-80^{\circ} \mathrm{C}$ until analysis.

\subsection{Organism index measurement}

The entire rumen from each yak was weighted after complete emptying of digesta and fluid. A rumen index was calculated using the following formula: Rumen index = Rumen weight (g)/Bodyweight (g) $\times 100 \%$.

\subsection{Histological examination}

Approximately $1 \mathrm{~cm}^{2}$ from the ventral sac of each rumen sample at each time point was harvested and fixed in $10 \%$ neutral buffered formalin for histological analysis. After fixation for at least $24 \mathrm{~h}$ at room temperature $\left(23^{\circ} \mathrm{C}\right)$, samples were dehydrated with alcohol, embedded in paraffin, cut into 5 - $\mu \mathrm{m}$ sections using a microtome (RM2016, Leica, Germany), and stained with hematoxylin and eosin (H.E). All slides were observed under a microscope (BA400Digital, MOTIC, China). Images were acquired using an imaging system connected to a light microscope (Nikon DS-Ri1, Japan). In total, 10 measurements were collected per yak rumen at each time point by Image-Pro Plus 6.0 (USA) image analysis software.

\subsection{Total DNA extraction}

Total DNA of each sample was extracted by QIAamp DNA Stool Kit (Qiagen, Hilden, Germany). Quality of DNA was assessed on $1 \%$ agarose gels. Then, DNA concentration was measured using the Qubit ${ }^{\circledR}$ dsDNA Assay Kit in Qubit® 2.0 Fluorometer (Life Technologies, CA, USA). The OD value for samples was between $1.8 \sim 2.0$, indicating high purity. More than $1 \mu \mathrm{g}$ of DNA was harvested from all samples, thus, they were deemed suitable for library construction.

\subsection{Library construction and sequencing}

A total of $1 \mu \mathrm{g}$ DNA per sample was used as input material. Sequencing libraries were generated by NEBNext ${ }^{\circledR}$ Ultra ${ }^{\text {TM }}$ DNA Library Prep Kit for Illumina (NEB, USA) according to the manufacturer's instructions. In short, the DNA sample was fragmented through sonication to a size of $350 \mathrm{bp}$, subsequently, DNA fragments were end-polished, a-tailed, and ligated with the full-length adaptor so as to Illumina sequencing by further PCR amplification. Lastly, PCR products were purified (AMPure XP system), and libraries were analyzed for size distribution using the Agilent 2100 Bioanalyzer and quantified by real-time PCR. The clusterings of index-coded samples were performed on a cBot Cluster Generation System following the manufacturer's recommendations. The libraries were sequenced using an Illumina HiSeq platform, and paired-end reads were analyzed behind cluster generation.

\subsection{Metagenome assembly and Gene prediction and annotation}


Preprocessing of the Raw Data obtained by the Illumina HiSeq sequencing platform was carried out to acquire Clean Data using Readfq V8. Considering the possibility of host pollution may exist in samples, a Blast of Clean Data to the host database was performed using default parameters using Bowtie2.2.4 software. The Clean Data were assembled and analyzed using SOAP denovo software V2.04 [22]. All reads not used in the forward step were integrated, and then the software of SOAP denovo was used for mixed assembly. Then, fragments shorter than $500 \mathrm{bp}$ in all Scaftigs created from the mixed or single assembly were filtered for further analysis.

Open reading frames (ORF) of Scaftigs ( $\geq 500 \mathrm{bp}$ ) were all predicted byMeta Gene Mark software Assessment of metagenomic assembly using simulated next generation sequencing data [23]. In order to perform ORF prediction, CD-HIT [24] software was adopted to remove redundancy and generate a unique initial gene catalog. Module and domain analyses were performed against the Pfam24.0 database using HMMER 3.0 [25]. The Clean Data from all samples were mapped to the initial gene catalogue using Bowtie 2.2.4[26]. The Unigenes were blasted to the sequences of Bacteria, Archaea, Fungi, and Viruses that were all extracted from the NR database at NCBI using DIAMOND software [27]. The abundance of species in one sample equaled the sum of the gene abundance annotated for the species. While the gene number of species in a sample equaled the number of genes with nonzero abundance. Unigenes were then blasted and annotated to functional databases using DIAMOND software V0.9.9 [28]. The functional database included the KEGG database, eggNOG database, and CAZy database. The best Blast Hit was used for subsequent analysis for each sequence's blast result.

\subsection{Statistical analysis}

All statistical analyses were performed with the SPSS 26.0 software (IBM Corp, Chicago, IL, USA). The rumen index, muscularis, and rumen papillae were evaluated using a fixed effects model of one way analysis of varianceone-way analysis of variance (ANOVA), followed by Tukey test. All statistical tests were assessed with a significance level of $5 \%$. The same statistical model was used for results shown in Fig. 3, Table 2, Table 3, 4 and 5.

\section{Results}

\subsection{Changes in the Rumen index}

There was no statistical difference in rumen index between the $0 \mathrm{~d}, 20 \mathrm{~d}$, and $60 \mathrm{~d}$ animals (Fig. 1). Then, a gradual increase in the rumen index was observed with age of the yak, with the index at $15 \mathrm{~m}$ being higher compared with $1 \mathrm{~d}, 20 \mathrm{~d}$, and $60 \mathrm{~d}$ groups $(P<0.05)$. The index for $5 \mathrm{y}$ animals was higher compared with the $15 \mathrm{~m}$ group $(P<0.05)$.

\subsection{Histology of the yak rumen}

The muscularis and rumen papillae could be measured accurately under a light microscope. The thickness of muscularis increased at every age point $(P<0.05)$. Regarding length and width or ruminal 
papillae, no differences were observed between $1 \mathrm{~d}$ and $20 \mathrm{~d}$ groups, but then gradually increased at each subsequent age point $(p<0.05)$. Tissue slices and morphometric parameters in each group of animals are shown in Figs. 2 and Table 1, respectively.

Table 1

Morphometric parameters of yak ruminal tissue at different ages.

\begin{tabular}{|llll|}
\hline Age & $\begin{array}{l}\text { Thickness of muscularis } \\
(\mathbf{m m})\end{array}$ & $\begin{array}{l}\text { Length of ruminal papillae } \\
(\mathbf{m m})\end{array}$ & $\begin{array}{l}\text { Width of ruminal papillae } \\
(\mathbf{m m})\end{array}$ \\
\hline $1 \mathrm{~d}$ & $757.7 \pm 138.44^{\mathrm{e}}$ & $359.65 \pm 79.06^{\mathrm{d}}$ & $130.03 \pm 38.86^{\mathrm{d}}$ \\
\hline $20 \mathrm{~d}$ & $956.21 \pm 327.49^{\mathrm{d}}$ & $391.71 \pm 150.67^{\mathrm{d}}$ & $160.61 \pm 41.16^{\mathrm{d}}$ \\
\hline $60 \mathrm{~d}$ & $1581.25 \pm 342.6^{\mathrm{c}}$ & $570.04 \pm 208.03^{\mathrm{c}}$ & $200.13 \pm 30.23^{\mathrm{c}}$ \\
\hline $15 \mathrm{~m}$ & $2135.82 \pm 291.82^{\mathrm{b}}$ & $735.12 \pm 297.22^{\mathrm{b}}$ & $255.1 \pm 60.52^{\mathrm{b}}$ \\
\hline $5 \mathrm{y}$ & $2339.51 \pm 300.32^{\mathrm{a}}$ & $1709.82 \pm 449.69^{\mathrm{a}}$ & $322.57 \pm 114.31^{\mathrm{a}}$ \\
\hline $\begin{array}{l}\text { Note: In the same column, the same small letter superscripts denote absence of significant difference } \\
(p>0.05), \text { whereas different small letter superscripts denote significant differences }(p<0.05) . \text { Data } \\
\text { represent mean } \pm \text { SD. }\end{array}$ & \\
\hline
\end{tabular}

\subsection{Microbial gene sequencing}

A total of 4,042,703 ORFs were obtained with an average of 252,669 per sample. A total of 2734,302 valid ORFs remained after removing redundancy and low-quality sequences, with an average length of 720.85 bp. There were 1951,597 genes among these sequences annotated by the NR database, which accounted for $71.37 \%$ of the total number of non-redundant genes. The proportions of all genes annotated to the boundary, phylum, class, order, family, genus, species-level were $71.14 \%, 66.81 \%, 66.19 \%, 57.39 \%, 53.48 \%$, and $34.12 \%$, respectively.

To explore differences in the number of genes among rumen microorganisms across different age groups, a box plot was generated according to gene annotation results (Fig. 3). There was a significant increase in the numbers of genes between the $1 \mathrm{~d}, 20 \mathrm{~d}$, and $15 \mathrm{~m}$ groups $(p<0.05)$. However, there was no statistical difference in the numbers of genes among the $60 \mathrm{~d}, 15 \mathrm{~m}$, and $5 \mathrm{y}$ animals (Fig. 3). A Venn Graph was drawn (Fig. 4) to better understand the distribution of gene numbers and analyze the common and unique information among them across different age points. There were 21,430 microbial genes shared by the five different age groups. Compared with other groups, the numbers of unique genes in group 1d, 20d, 60d, 15m, 5y were 97,619, 123,875, 203,321, 105,329, and 106,777, respectively.

\subsection{Ruminal microbial composition}

At the phylum level, relative abundance results indicated that Bacteroidetes and Firmicutes were the two phyla with the highest abundance across the five different groups. Secondly, Proteobacteria had the highest relative abundance in group $20 \mathrm{~d}$ and the lowest relative abundance in group $15 \mathrm{~m}$. The relative 
abundance of Fibrobacteres was the highest in $60 \mathrm{~d}$ group and the lowest in $1 \mathrm{~d}$ group. The relative abundance of Proteobacteria was the highest in group 5y and the lowest in group $1 \mathrm{~d}$. The relative abundance of Spirochaetes was the highest in $60 \mathrm{~d}$ group and the lowest in $1 \mathrm{~d}$ group. The relative abundance of Chytridiomycota was the highest in $15 \mathrm{~m}$ group and the lowest in $1 \mathrm{~d}$ group. Furthermore, the relative abundance of Fusobacteria was the highest in group $1 \mathrm{~d}$ and the lowest in group 5y. Ascomycota had the highest relative abundance in the $15 \mathrm{~m}$ group and the lowest relative abundance in the $1 \mathrm{~d}$ group. The relative abundance of Lentisphaerae was highest in the $\mathrm{t} 20 \mathrm{~d}$ group and lowest in the $1 \mathrm{~d}$ group. Verrucomicrobia had the highest relative abundance in the $1 \mathrm{~d}$ group and the lowest relative abundance in the $15 \mathrm{~m}$ group. Phylum and genus levels relative abundance is shown in Fig. 5 . At the genus level, the two genera with the highest relative abundance in the $1 \mathrm{~d}$ and $20 \mathrm{~d}$ group were Bacteroides and Porphyromonas. The two genera with the highest relative abundance in groups $60 \mathrm{~d}$ and $15 \mathrm{~m}$ were Prevotella and Butyrivibrio. The two highest genera in the $5 y$ group were Bacteroides and Prevotella.

\subsection{Comparison of CAZy of yak rumen at different ages}

A total of 115401 genes were annotated on the CAZy database. The Glycoside Hydrolase (GH) had the highest relative abundance, followed by Glycosyl Transferase (GT), and Carbohydrate-binding Modules (CBM). There was an obvious difference in CAZy between the 5 groups. Furthermore, the relative abundance of glycoside hydrolase $(\mathrm{GH})$ was the highest in the $5 y$ group and lowest in the $15 \mathrm{~m}$ group. The relative abundance of GT was the highest in the $1 \mathrm{~d}$ group and lowest in the $15 \mathrm{~m}$ group. Furthermore, the relative abundance of the carbohydrate-binding module (CBM) was highest in the $5 y$ group and lowest in the $1 \mathrm{~d}$ group. The relative abundance of carbohydrate esterase (CE) was the highest in the 5y group and lowest in the $1 \mathrm{~d}$ group. In addition, the relative abundance of polysaccharide lyase $(\mathrm{PL})$ was the highest in the $60 \mathrm{~d}$ group and lowest in the $20 \mathrm{~d}$ group. The expression of auxiliary active enzyme system (AA) was low in all groups. The components of the GH and GT family had some obvious changes among the 5 groups (Table 2). 
Table 2

High abundance enzymes from CAZy.

\begin{tabular}{|c|c|c|c|c|c|c|}
\hline CAZy & enzyme & 1d & $20 d$ & $60 d$ & $15 \mathrm{~m}$ & $5 y$ \\
\hline \multirow[t]{5}{*}{$\begin{array}{l}\mathrm{GH} \\
\text { family }\end{array}$} & $\mathrm{GH} 49$ & $\begin{array}{l}50683.08 \pm \\
14224.73^{c}\end{array}$ & $\begin{array}{l}45732.77 \pm \\
46537.9^{c}\end{array}$ & $\begin{array}{l}107700.17 \pm \\
9416.98^{\mathrm{ab}}\end{array}$ & $\begin{array}{l}68307.15 \pm \\
11302.2^{b c}\end{array}$ & $\begin{array}{l}139356.99 \pm \\
10278.2^{\mathrm{a}}\end{array}$ \\
\hline & $\mathrm{GH} 64$ & $\begin{array}{l}69869.37 \pm \\
9987.66^{\mathrm{bc}}\end{array}$ & $\begin{array}{l}54914.32 \pm \\
27782.79^{\text {cd }}\end{array}$ & $\begin{array}{l}83287.31 \pm \\
6407.59^{\mathrm{ab}}\end{array}$ & $\begin{array}{l}42974.35 \pm \\
8827.88^{d}\end{array}$ & $\begin{array}{l}100465.29 \pm \\
8656.36^{\mathrm{a}}\end{array}$ \\
\hline & $\mathrm{GH} 44$ & $\begin{array}{l}36382.51 \pm \\
4033.2^{c}\end{array}$ & $\begin{array}{l}54496.49 \pm \\
33531.94^{\mathrm{bc}}\end{array}$ & $\begin{array}{l}76205.43 \pm \\
4944.73^{b}\end{array}$ & $\begin{array}{l}48534.79 \pm \\
9036.65^{b c}\end{array}$ & $\begin{array}{l}112415.14 \pm \\
15898.4^{\mathrm{a}}\end{array}$ \\
\hline & $\mathrm{GH} 128$ & $\begin{array}{l}37083.52 \pm \\
4743.07^{\mathrm{ab}}\end{array}$ & $\begin{array}{l}33509.35 \pm \\
9476.76^{b}\end{array}$ & $\begin{array}{l}37581.69 \pm \\
1973.58^{\mathrm{ab}}\end{array}$ & $\begin{array}{l}17685.08 \pm \\
4131.1^{c}\end{array}$ & $\begin{array}{l}43961.36 \pm \\
5083.54^{\mathrm{a}}\end{array}$ \\
\hline & $\mathrm{GH} 124$ & $\begin{array}{l}40142.37 \pm \\
1012.98^{a}\end{array}$ & $\begin{array}{l}32827.52 \pm \\
9557.79^{a b}\end{array}$ & $\begin{array}{l}20675.4 \pm \\
2980.4^{b c}\end{array}$ & $\begin{array}{l}12737.18 \pm \\
2411.65^{c}\end{array}$ & $\begin{array}{l}41953.14 \pm \\
12576.05^{a}\end{array}$ \\
\hline \multirow[t]{5}{*}{$\begin{array}{l}\text { GT } \\
\text { family }\end{array}$} & GT2 & $\begin{array}{l}117926.43 \pm \\
944.06^{a}\end{array}$ & $\begin{array}{l}93097 \pm \\
12552.43^{b}\end{array}$ & $\begin{array}{l}87005.67 \pm \\
3838.36^{\mathrm{bc}}\end{array}$ & $\begin{array}{l}37266.28 \pm \\
6978.17^{d}\end{array}$ & $\begin{array}{l}74136.56 \pm \\
6701.22^{\mathrm{c}}\end{array}$ \\
\hline & GT4 & $\begin{array}{l}36250.45 \pm \\
15204.18^{a}\end{array}$ & $\begin{array}{l}34055.41 \pm \\
6167.37^{a}\end{array}$ & $\begin{array}{l}28758.08 \pm \\
2395.37^{a}\end{array}$ & $\begin{array}{l}11970.61 \pm \\
2796.75^{b}\end{array}$ & $\begin{array}{l}31479.87 \pm \\
4131.47^{a}\end{array}$ \\
\hline & GT51 & $\begin{array}{l}31024.68 \pm \\
7932.13^{a}\end{array}$ & $\begin{array}{l}23267.64 \pm \\
3136.45^{a}\end{array}$ & $\begin{array}{l}23253.41 \pm \\
777.72^{\mathrm{a}}\end{array}$ & $\begin{array}{l}9974.31 \pm \\
2834.25^{\mathrm{b}}\end{array}$ & $\begin{array}{l}29978.55 \pm \\
3835.32^{\mathrm{a}}\end{array}$ \\
\hline & GT35 & $\begin{array}{l}10909.55 \pm \\
556.49^{c}\end{array}$ & $\begin{array}{l}17280.15 \pm \\
5908.72^{\mathrm{ab}}\end{array}$ & $\begin{array}{l}16960.14 \pm \\
145.81^{\mathrm{ab}}\end{array}$ & $\begin{array}{l}15250.14 \pm \\
1749.57^{b c}\end{array}$ & $\begin{array}{l}21900.06 \pm \\
2497.93^{a}\end{array}$ \\
\hline & GT5 & $\begin{array}{l}12857.43 \pm \\
2246.09^{a}\end{array}$ & $\begin{array}{l}13024.92 \pm \\
2092.98^{a}\end{array}$ & $\begin{array}{l}10816.18 \pm \\
844.18^{\mathrm{ab}}\end{array}$ & $\begin{array}{l}8061.36 \pm \\
631.94^{\mathrm{b}}\end{array}$ & $\begin{array}{l}12353.54 \pm \\
1585.75^{a}\end{array}$ \\
\hline
\end{tabular}

\subsection{Comparative functional analysis of ruminal microbiomes}

Based on the eggNOG and KEGG database analysis, the annotated statistical results of functional protein differences among groups revealed that the highest abundance in the $1 \mathrm{~d}$ and $20 \mathrm{~d}$ groups was related to replication, recombination, and repair proteins and translation proteins. The highest abundance in the a60d and 5y groups was related to carbohydrate transport and metabolic proteins. The proteins with the highest relative abundance in the $15 \mathrm{~m}$ group were signal transduction mechanism proteins (Table 3 ). In addition, differences in the abundance of 6 metabolic pathways from the KEGG database annotated among groups are shown in Table 4. The highest abundance of metabolic pathways was metabolism, followed by genetic information processing and environmental information processing. 
Table 3

Relative abundance of different functional proteins.

\begin{tabular}{|llllll|}
\hline Protein function category & $\mathbf{1 d}$ & $\mathbf{2 0 d}$ & $\mathbf{6 0 d}$ & $\mathbf{1 5 m}$ & $\mathbf{5 y}$ \\
\hline Replication, recombination and repair & $6.83 \pm$ & $5.34 \pm$ & $4.6 \pm$ & $1.87 \pm$ & $3.88 \pm$ \\
& $1.01^{\mathrm{a}}$ & $1.04^{\mathrm{b}}$ & $0.37^{\mathrm{bc}}$ & $0.48^{\mathrm{d}}$ & $0.25^{\mathrm{c}}$ \\
\hline Cell wall/membrane/envelope & $5.2^{ \pm}$ & $4.29 \pm$ & $3.83 \pm$ & $1.43 \pm$ & $3.58 \pm$ \\
biogenesis & $0.74^{\mathrm{a}}$ & $0.43^{\mathrm{b}}$ & $0.14^{\mathrm{b}}$ & $0.37^{\mathrm{c}}$ & $0.31^{\mathrm{b}}$ \\
\hline Carbohydrate transport and & $4.19 \pm$ & $4.09 \pm$ & $4.77 \pm$ & $2.72 \pm$ & $5.42 \pm$ \\
metabolism & $0.17^{\mathrm{b}}$ & $1.16^{\mathrm{ab}}$ & $0.13^{\mathrm{ab}}$ & $0.47^{\mathrm{c}}$ & $0.5^{\mathrm{a}}$ \\
\hline Translation, ribosomal structure and & $5.28 \pm$ & $5.28 \pm$ & $4.43 \pm$ & $2.62 \pm$ & $5.28 \pm$ \\
biogenesis & $0.2^{\mathrm{a}}$ & $0.05^{\mathrm{b}}$ & $0.21^{\mathrm{b}}$ & $0.48^{\mathrm{c}}$ & $0.48^{\mathrm{a}}$ \\
\hline Amino acid transport and & $4.6 \pm$ & $4.53 \pm$ & $4.02 \pm$ & $1.8 \pm$ & $4.46 \pm$ \\
metabolism & $0.28^{\mathrm{a}}$ & $0.25^{\mathrm{a}}$ & $0.2^{\mathrm{a}}$ & $0.44^{\mathrm{b}}$ & $0.49^{\mathrm{a}}$ \\
\hline Inorganic ion transport and & $4.08 \pm$ & $2.94 \pm$ & $2.62 \pm$ & $1.22 \pm$ & $2.95 \pm$ \\
metabolism & $0.62^{\mathrm{a}}$ & $0.29^{\mathrm{b}}$ & $0.07^{\mathrm{b}}$ & $0.28^{\mathrm{c}}$ & $0.34^{\mathrm{b}}$ \\
\hline Energy production and conversion & $3.46 \pm$ & $3.64 \pm$ & $3.09 \pm$ & $1.6 \pm$ & $3.62 \pm$ \\
& $0.1^{\mathrm{a}}$ & $0.3^{\mathrm{a}}$ & $0.17^{\mathrm{a}}$ & $0.35^{\mathrm{b}}$ & $0.42^{\mathrm{a}}$ \\
\hline Transcription & $3.14 \pm$ & $2.8 \pm$ & $2.54 \pm$ & $1.27 \pm$ & $2.3 \pm 0.2^{\mathrm{c}}$ \\
\hline Signal transduction mechanisms & $1.9 \pm$ & $1.57 \pm$ & $2.18 \pm$ & $2.93 \pm$ & $1.71 \pm$ \\
& $0.06^{\mathrm{bc}}$ & $0.24^{\mathrm{c}}$ & $0.2^{\mathrm{b}}$ & $0.02^{\mathrm{a}}$ & $0.23^{\mathrm{c}}$ \\
\hline
\end{tabular}

Figure 3. Box plot of gene number differences among groups. Similar shoulder labels of the same data indicate lack of statistical differences $(P>0.05)$. Different lower case letters denote statistical differences $(P<0.05)$. 
Table 4

Results of six metabolic pathways.

\begin{tabular}{|c|c|c|c|c|c|}
\hline KO passway & 1d & $20 d$ & $60 d$ & & $5 y$ \\
\hline Metabolism & $\begin{array}{l}15.4 \pm \\
1.09^{a}\end{array}$ & $\begin{array}{l}14.04 \pm \\
0.2^{\mathrm{ab}}\end{array}$ & $\begin{array}{l}12.19 \pm \\
0.58^{b}\end{array}$ & $\begin{array}{l}5.72 \pm \\
1.24^{\mathrm{c}}\end{array}$ & $\begin{array}{l}13.49 \pm \\
1.37^{b}\end{array}$ \\
\hline Genetic Information Processing & $\begin{array}{l}5.69 \pm \\
0.29^{a}\end{array}$ & $\begin{array}{l}5.65 \pm \\
0.19^{a}\end{array}$ & $\begin{array}{l}5.01 \pm \\
0.15^{b}\end{array}$ & $\begin{array}{l}3.48 \pm \\
0.49^{\mathrm{c}}\end{array}$ & $\begin{array}{l}6.04 \pm \\
0.46^{\mathrm{a}}\end{array}$ \\
\hline $\begin{array}{l}\text { Environmental Information } \\
\text { Processing }\end{array}$ & $\begin{array}{l}2.58 \pm \\
0.26\end{array}$ & $\begin{array}{l}2.53 \pm \\
0.21\end{array}$ & $\begin{array}{l}2.45 \pm \\
0.01\end{array}$ & $\begin{array}{l}2.44 \pm \\
0.13\end{array}$ & $2.4 \pm 0.1$ \\
\hline Cellular Processes & $\begin{array}{l}2.06 \pm \\
0.2^{b}\end{array}$ & $\begin{array}{l}2.05 \pm \\
0.05^{b}\end{array}$ & $2.12 \pm 0.1^{\mathrm{b}}$ & $\begin{array}{l}2.41 \pm \\
0.09^{a}\end{array}$ & $\begin{array}{l}2.16 \pm \\
0.05^{\mathrm{b}}\end{array}$ \\
\hline Human Diseases & $\begin{array}{l}1.7 \pm \\
0.15^{b}\end{array}$ & $\begin{array}{l}1.54 \pm \\
0.02^{\mathrm{bc}}\end{array}$ & $1.5 \pm 0.12^{c}$ & $\begin{array}{l}2.04 \pm \\
0.05^{\mathrm{a}}\end{array}$ & $\begin{array}{l}1.63 \pm \\
0.08^{b c}\end{array}$ \\
\hline Organismal Systems & $\begin{array}{l}0.74 \pm \\
0.08^{\mathrm{c}}\end{array}$ & $\begin{array}{l}0.79 \pm \\
0.12^{b}\end{array}$ & $\begin{array}{l}0.93 \pm \\
0.16^{\mathrm{bc}}\end{array}$ & $\begin{array}{l}1.87 \pm \\
0.04^{\mathrm{a}}\end{array}$ & $\begin{array}{l}1.12 \pm \\
0.11^{\mathrm{c}}\end{array}$ \\
\hline
\end{tabular}

Figure 3. Box plot of gene number differences among groups.Similar shoulder labels of the same data indicate lack of statistical differences $(P>0.05)$. Different lower case letters denote statistical differences $(P<0.05)$.

\section{Discussion}

The yak has unique physiological mechanisms to adapt to the cold and low-oxygen environment of the Tibetan plateau [29]. The impact of ruminal microbiota and tissue on production efficiency of Yak is undeniable. It is widely acknowledged that the rumen is incompletely developed both metabolically and physically at birth [4]. During the first weeks of life, when the animals are still suckling milk, the rumen is not functional: the suckled milk does not pass through it due to closure of the esophageal groove (the "nursing reflex"). The relative proportions of the rumen are smaller than that in the adult, and some of its functional components such as the rumen wall papillae, which serve to absorb volatile fatty acids, are not yet developed [21]. In neonates, the rumen does not have the high degree of keratinization characteristic of the mature organ. Following the initiation of solid feed intake by the neonate and the subsequent establishment of ruminal fermentation, the rumen goes through both physical and metabolic development. Physical development of the rumen can be further segmented into 2 aspects: growth of the papillae and increases in rumen mass [14]. Changes in the physiological and structural properties of the rumen with age are connected with the development of microorganisms, as their fermentation products are crucial for the development of the rumen wall papillae. In our study, the rumen index rose gradually from 1 day to 5 years of age, underscoring how the rumen plays a more important role as the yak grows older. 
The extent of morphophysiological variation in the yak rumen reveals a degree of adaptability to a particular feed. The mature yak had longer and wider papillae in the rumen during the green compared with the dry season. Although the number of papillae and muscular thickness of the rumen did not significantly change between the green and dry seasons, the width and length of papillae increased in the green compared with the dry season [16]. Physical stimulation by feed should lead to measurable increases in both musculature development and rumen weight. When milk is infused directly into the rumen, resulting in short-chain fatty acids (SCFA) production, papillary growth is stimulated. In this study, the thickness of muscularis, length, and width of rumen nipple of the yak rumen increased gradually from $1 \mathrm{~d}$ to $5 \mathrm{y}$ of age, which were mainly driven by physical development and diets, contributing to increasing the absorption of nutrients in the yak rumen.

Despite inter-species diversities in community structure and function, ruminal microbiota play a beneficial role in host metabolism and immunity across various species [30]. In ruminants, the common ruminal microbes are Fibrobacter succinogenes, Ruminococcus albus, Butyrivibrio fifibrisolvens, Ruminococcus fflavefaciens, and Prevotella [31]. Bacteroidetes and Firmicutes were the predominant bacterial phyla in the yak rumen [11]. While, Firmicutes, Fibrobacteres, Bacteroidetes, Euryarchaeota, and Proteobacteria were the predominant phyla in the cattle-yak rumen microbial community [10]. The rumen microbial groups varied through the growth of yaks from neonatal to adult and compared with the protozoan and fungal groups, the bacterial and archaeal groups were more sensitive to changes in growth stages [32]. A total of 7200 operational taxonomic units (OTUs) were gained from the yak rumen using 16S rRNA gene sequencing, and 23 phyla within 159 families were identified by taxonomic summarization [18]. Different forage growth stages changed the diversity, composition, and function of ruminal microbiota in the yaks which grazed naturally without feed supplementation in the alpine meadow of the Qinghai-Tibet Plateau [16]. Temperature changes likely had a direct effect on plant productivity, which in turn influenced the ruminal microbiome of both male and female yak.

Previous studies showed that the diversity and number of the organisms residing within the gut ecosystem are regulated by physiological and environmental factors including habitat and diet [33]. Ruminal microbes constantly interact among themselves and with the host ruminal epithelia. Different types of interactions are present, but most are commensal. The composition of the microbial community changes obviously between and within host species, suggesting that host genetics could influence functional genetic potentials of the rumen microbiome [33]. Seven individual yaks from four altitude populations clustered together, suggesting that the yak's gut microbiota is extremely conserved for interspecies comparisons, despite inter-individual variation [15]. Diet also plays an important role in determining the composition of the resident gut microbes [34, 35]. Therefore, both host genotype and diet were likely to be major factors in determining the composition of the resident ruminal microbes.

There are now various approaches for studying ruminal microbiota, for instance, denaturing gradient gel electrophoresis, temperature gradient gel electrophoresis, real-time PCR, high-throughput sequencing of 16S rRNA gene, and metagenomics. Among these methods, metagenomic analysis can more truly reflect the microbial composition and interaction in the sample and enables the identification of novel genes 
and proteins of industrial interest [36,37]. In the present study, we investigated the metagenomics of the yak rumen at 5 different ages. Relative abundance results showed that Bacteroidetes and Firmicutes were the two phyla with the highest abundance in 5 groups, which were in accordance with a report in mature yak [11]. There were obvious differences in microbes between the 5 groups, which also revealed rumen microorganisms were in a dynamic process and might mainly be regulated by host genotype and diet within different growth stages.

Functional metagenomics has the potential to discover new enzymes and metabolic pathways in the rumen in case of innovative strategies for screening are developed. The enzymatic machinery necessary to hydrolyze structural plant polysaccharides is an important target, though a new carbohydrate-binding domain has been reported in buffalo rumens [38]. One-hundred fifty glycoside hydrolase (GH) genes were annotated as fibrinolytic proteins in the yak rumen, and the majority $(69 \%)$ were clustered or linked with genes encoding related functions. The predominant cellulase/ hemicellulase genes were $\mathrm{GH} 5, \mathrm{GH} 9$, and $\mathrm{GH} 10$, yet no GH48 exocellulase gene was detected. These findings suggested that the SucC/SucDinvolving mechanism plays a vital role in lignocellulose degradation in yak rumen [19]. Recently, a total of 145,489 genes were annotated using the Carbohydrate-active Enzymedatabase, which identified GH as the most highly represented enzyme family in the cattle-yak rumen [10]. In our study, a total of 115,401 genes were annotated on the CAZy database. The glycoside hydrolase $(\mathrm{GH})$ had the highest relative abundance, followed by glycosyltransferase (CT), and carbohydrate-binding modules (CBM). The discrepancies between the above reports may be due to the differences in animals and methods that have been applied. These newly discovered genes and enzymes need to be further studied to facilitate their possible application in breeding production.

\section{Conclusions}

In summary, the present study investigated the morphological and metagenomic analyses of the yak rumen in newborn yaks and their changes at different growth stages. Collectively, our present findings and previous work highlight that the morphology and microorganisms in the yak rumen were in a complex dynamic process and might be mainly influenced by host genotype and diet. Integrative knowledge about the interactions between microbial composition and age in the yak rumen could provide new insights into ruminal microbial functions that benefit the development of modern yak husbandry strategies.

\section{Declarations}

Author Contributions: L.W. and M.J. conceived and designed this study. J.L. performed experiments, analyzed data and collected sample collection. AA and JJL interpreted data and edited the paper. All authors reviewed and approved the final manuscript.

Funding: This research was supported by Sichuan Science and Technology Program(2019YFH0035), and the Fundamental Research Funds for the Central Universities $₫$ Southwest Minzu University (2021PTJS20). 
Acknowledgments: Not applicable.

Conflicts of Interest: The authors declare no conflict of interest.

\section{References}

1. Morgavi DP, Kelly WJ, Janssen PH, Attwood GT. Rumen microbial (meta)genomics and its application to ruminant production. Animal. 2012;7:184-201.

2. Deng W, Xi D, Mao H, Wanapat M. The use of molecular techniques based on ribosomal RNA and DNA for rumen microbial ecosystem studies: a review. Mol Biol Rep. 2008;35:265-74.

3. Guan LL, Nkrumah JD, Basarab JA, Moore SS. Linkage of microbial ecology to phenotype: Correlation of rumen microbial ecology to cattle's feed efficiency. FEMS Microbiol Lett. 2008;288:8591.

4. Zhou M, Hernandezsanabria E, Guan LL. Assessment of the Microbial Ecology of Ruminal Methanogens in Cattle with Different Feed Efficiencies. Appl Environ Microbiol. 2009;75:6524.

5. Hess M, Sczyrba A, Egan R, Kim TW, Chokhawala H, Schroth G, Luo S, Clark DS, Chen F, Zhang T, Mackie RI, Pennacchio LA, Tringe SG, Visel A, Woyke T, Wang Z, Rubin EM. Metagenomic discovery of biomass-degrading genes and genomes from cow rumen. Science. 2011;331:463-7.

6. Ross EM, Moate PJ, Bath CR, Da Vidson SE, Sawbridge TI, Guthridge KM, Cocks BG, Hayes BJ. High throughput whole rumen metagenome profiling using untargeted massively parallel sequencing. BMC Genet. 2012;13:53.

7. Maman LG, Palizban F, Atanaki FF, Ghiasi NE, Kavousi K. Co-abundance analysis reveals hidden players associated with high methane yield phenotype in sheep rumen microbiome. Sci Rep. 2020;10:4995.

8. Zhang Y, Li F, Chen Y, Wu H, Guan LL. Metatranscriptomic Profiling Reveals the Effect of Breed on Active Rumen Eukaryotic Composition in Beef Cattle With Varied Feed Efficiency. Front Microbiol. 2020;11:367.

9. Singh KM, Reddy B, Patel AK, Panchasara H, Parmar N, Patel AB, Shah TM, Bhatt VD, Joshi CG. Metagenomic analysis of buffalo rumen microbiome: Effect of roughage diet on Dormancy and Sporulation genes. Meta Gene. 2014;2:252-68.

10. Sha Y, Hu J, Shi B, Dingkao R, Liu X Characteristics and Functions of the Rumen Microbial Community of Cattle-Yak at Different Ages. Biomed. Res. Int. 2020, 2020, 1-9.

11. Liu C, Wu H, Liu S, Chai S, Zhou Z. Dynamic alterations in yak rumen bacteria community and metabolome characteristics in response to feed type. Front Microbiol. 2019;10:1116.

12. Gu Z, Zhao X, Ning L, Wu C. Complete sequence of the yak (Bos grunniens) mitochondrial genome and its evolutionary relationship with other ruminants. Mol Phylogenet Evol. 2007;42:248-55.

13. Harris, Rb. Rangeland degradation on the Qinghai-Tibetan plateau: a review of the evidence of its magnitude and causes. J Arid Environ. 2010;74:1-12. 
14. Baldwin RL, Connor E. Rumen Function and Development. Vet Clin Food Anim. 2017;33:427-39.

15. Zhang Z, Xu D, Wang L, Hao J, Wang J, Zhou X, Wang W, Qiu Q, Huang X, Zhou J. Convergent Evolution of Rumen Microbiomes in High-Altitude Mammals. Curr Biol. 2016;26:1873-9.

16. Ma L, Xu S, Liu H, Xu T, Zhang X. Yak rumen microbial diversity at different forage growth stages of an alpine meadow on the Qinghai-Tibet Plateau. PeerJ. 2019;7:e7645.

17. Wang LZ, Wang ZS, Xue B, De WU, Peng QH. Comparison of rumen archaeal diversity in adult and elderly yaks (Bos grunniens) using 16S rRNA gene high-throughput sequencing. J Integr Agric. 2017;16:1130-7.

18. Wei G, Ying L, Wang L, Wang J, Ba I. X. Evaluation of Composition and Individual Variability of Rumen Microbiota in Yaks by $16 \mathrm{~S}$ rRNA High-throughput Sequencing Technology. Anaerobe. 2015;34:74-9.

19. Dai X, Zhu Y, Luo Y, Song L, Liu D, Liu L, Chen F, Wang M, Li J, Zeng X. Metagenomic Insights into the Fibrolytic Microbiome in Yak Rumen. Plos One. 2012;7:e40430.

20. Tajima K, Arai S, Ogata K, Nagamine T, Matsui H, Nakamura M, Aminov RI, Benno Y. Rumen Bacterial Community Transition During Adaptation to High-grain Diet. Anaerobe 2000, 6, 273-284.

21. Jami E, Israel A, Kotser A, Mizrahi I. Exploring the bovine rumen bacterial community from birth to adulthood. ISME J. 2013;7:1069-79.

22. Luo R, Liu B, Xie Y, Li Z, Huang W, Yuan J, He G, Chen Y, Pan Q, Liu Y, Tang J, Wu G, Zhang H, Shi Y, Liu Y, Yu C, Wang B, Lu Y, Han C, Cheung DW, Wang J SOAPdenovo2: an empirically improved memory-efficient short-read de novo assembler. GigaScience 2012, 1, 18.

23. Mende DR, Waller AS, Sunagawa S, Järvelin Al, Chan MM, Arumugam M, Raes J, Bork P. Assessment of metagenomic assembly using simulated next generation sequencing data. PloS one. 2012;7(2):e31386.

24. Mende DR, Waller AS, Sunagawa S, Järvelin Al, Chan MM, Arumugam M, Raes J, Bork P. Assessment of metagenomic assembly using simulated next generation sequencing data. PloS One. 2012;7:e31386.

25. Prakash A, Jeffryes M, Bateman A, Finn RD The HMMER Web Server for Protein Sequence Similarity Search. curr. protoc. Bioinformatics 2017, 60, 3.15.1-3.15.23.

26. Bahram M, Hildebrand F, Forslund SK, Anderson JL, Soudzilovskaia NA, Bodegom PM, BengtssonPalme J, Anslan S, Coelho LP, Harend H, Huerta-Cepas J, Medema MH, Maltz MR, Mundra S, Olsson PA, Pent M, Põlme S, Sunagawa S, Ryberg M, Tedersoo L, Bork P. Structure and function of the global topsoil microbiome. Nature. 2018;560:233-7.

27. Buchfink B, Xie C, Huson DH. Fast and sensitive protein alignment using DIAMOND. Nat Methods. 2015;12(1):59-60.

28. Yu J, Blom J, Sczyrba A, Goesmann A. Rapid protein alignment in the cloud: HAMOND combines fast DIAMOND alignments with Hadoop parallelism. J Biotechnol. 2017;257:58-60. 
29. Xue D, Chen H, Zhao X, Xu S, Hu L, Xu T, Jiang L, Zhan W. Rumen prokaryotic communities of ruminants under different feeding paradigms on the Qinghai-Tibetan Plateau. Syst Appl Microbiol. 2017;40:227-36.

30. Tilg H, Kaser A. Gut microbiome, obesity, and metabolic dysfunction. J Clin Invest. 2011;121:212632.

31. Flint HJ, Bayer EA, Rincon MT, Lamed R, White BA. Polysaccharide utilization by gut bacteria: potential for new insights from genomic analysis. Nat Rev Microbiol. 2008;6:121-31.

32. Guo W, Zhou M, Ma T, Bi S, Wang W, Zhang Y, Huang X, Guan LL, Long R Survey of rumen microbiota of domestic grazing yak during different growth stages revealed novel maturation patterns of four key microbial groups and their dynamic interactions. Anim. Microbiome. 2020, 2, 23.

33. Mandal RS, Saha S, Das S. Metagenomic Surveys of Gut Microbiota. Genomics Proteomics Bioinformatics. 2015;13:148-58.

34. Pathak AK. Various factors affecting microbial protein synthesis in the rumen. Vet World. 2008;1:186-9.

35. Turnbaugh PJ, Ridaura VK, Faith JJ, Rey FE, Knight R, Gordon JI. The Effect of Diet on the Human Gut Microbiome: A Metagenomic Analysis in Humanized Gnotobiotic Mice. Sci Transl Med. 2009;1:6ra14.

36. Rubin S, Mering CV, Kobayashi A, Salamov AA, Chen K, Chang HW, Podar M, Short JM, Mathur EJ, Detter JC. Comparative metagenomics of microbial communities. Science. 2005;308:554-7.

37. Roumpeka DD, John WR, Frank E, lan F, Mick, W. A Review of Bioinformatics Tools for BioProspecting from Metagenomic Sequence Data. Front Genet. 2017;8:23.

38. Duan CJ, Xian L, Zhao GC, Feng Y, Pang H, Bai XL, Tang JL, Ma QS, Feng JX. Isolation and partial characterization of novel genes encoding acidic cellulases from metagenomes of buffalo rumens. $J$ App/Microbiol. 2009;107:245-56.

\section{Figures}




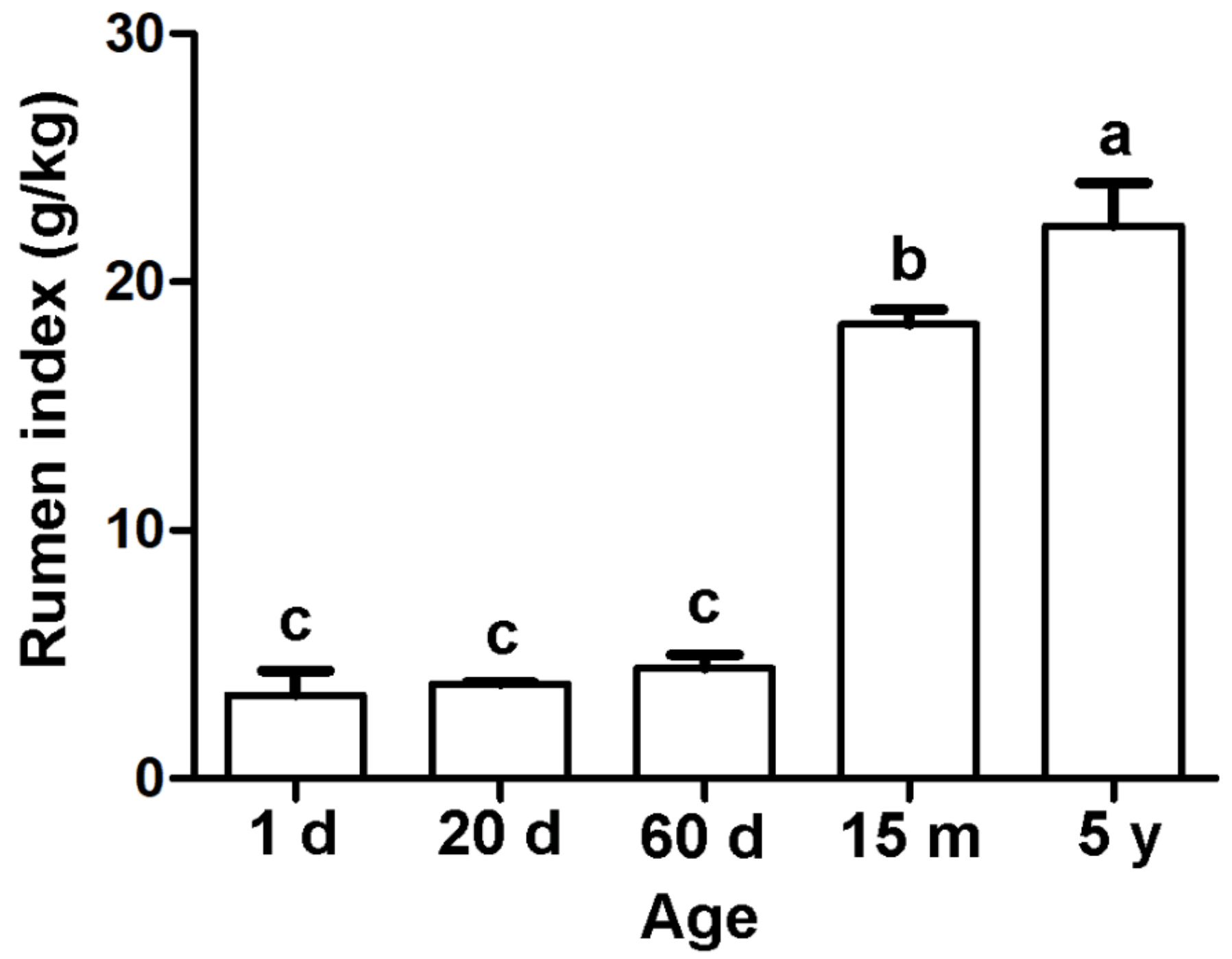

Figure 1

Rumen indices of yaks at different ages. Note: The same small letter superscripts denote absence of significant difference $(p>0.05)$, whereas different small letter super-scripts denote significant differences $(p<0.05)$. 

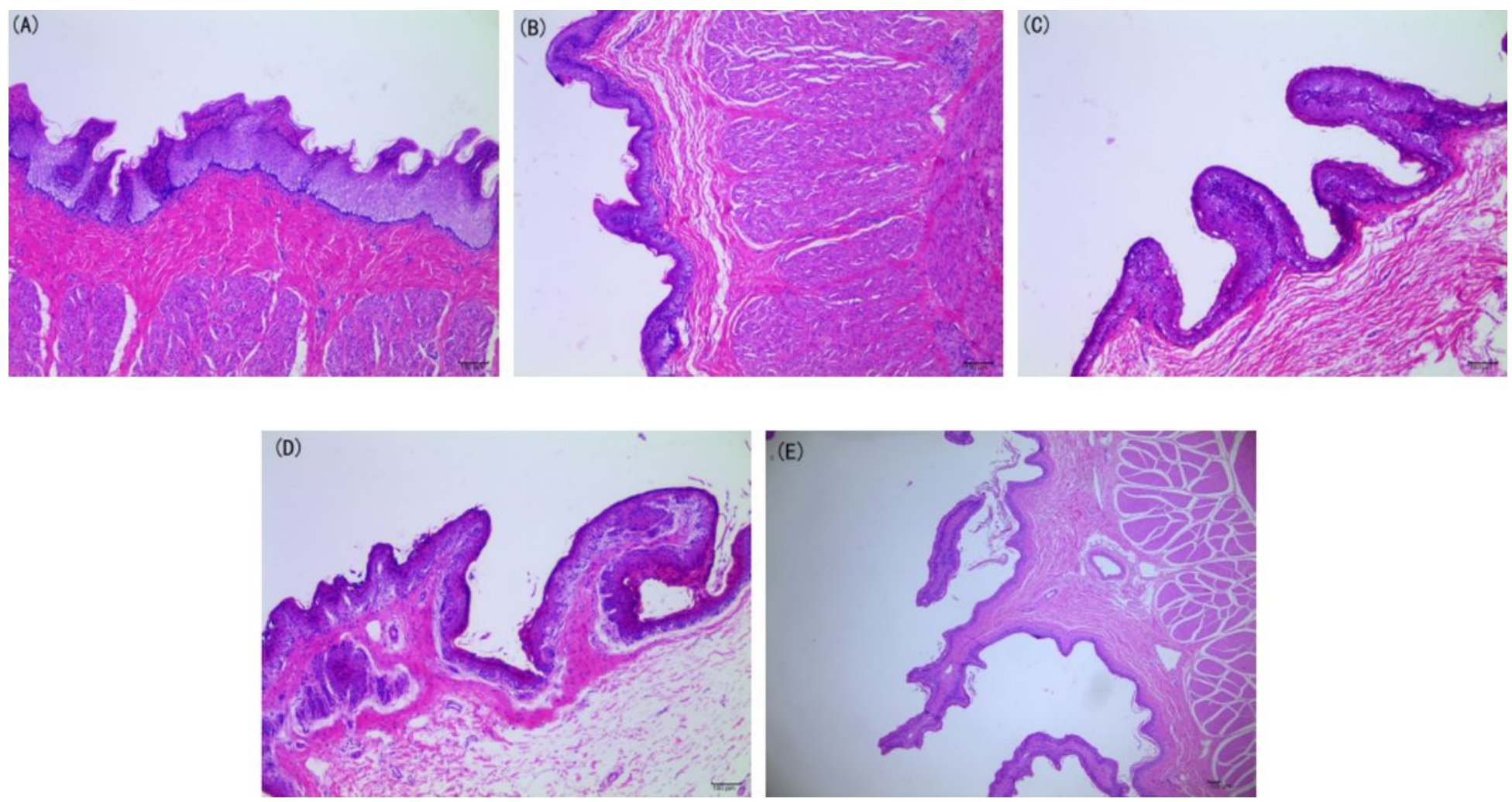

Figure 2

Light photomicrograph of yak ruminal tissue slices at different ages. (A) 1d, (B) 20d,(C)60d,(D)15m, (E)5y, (A-D) H.E.ख1000 (E) H.E.囚400 


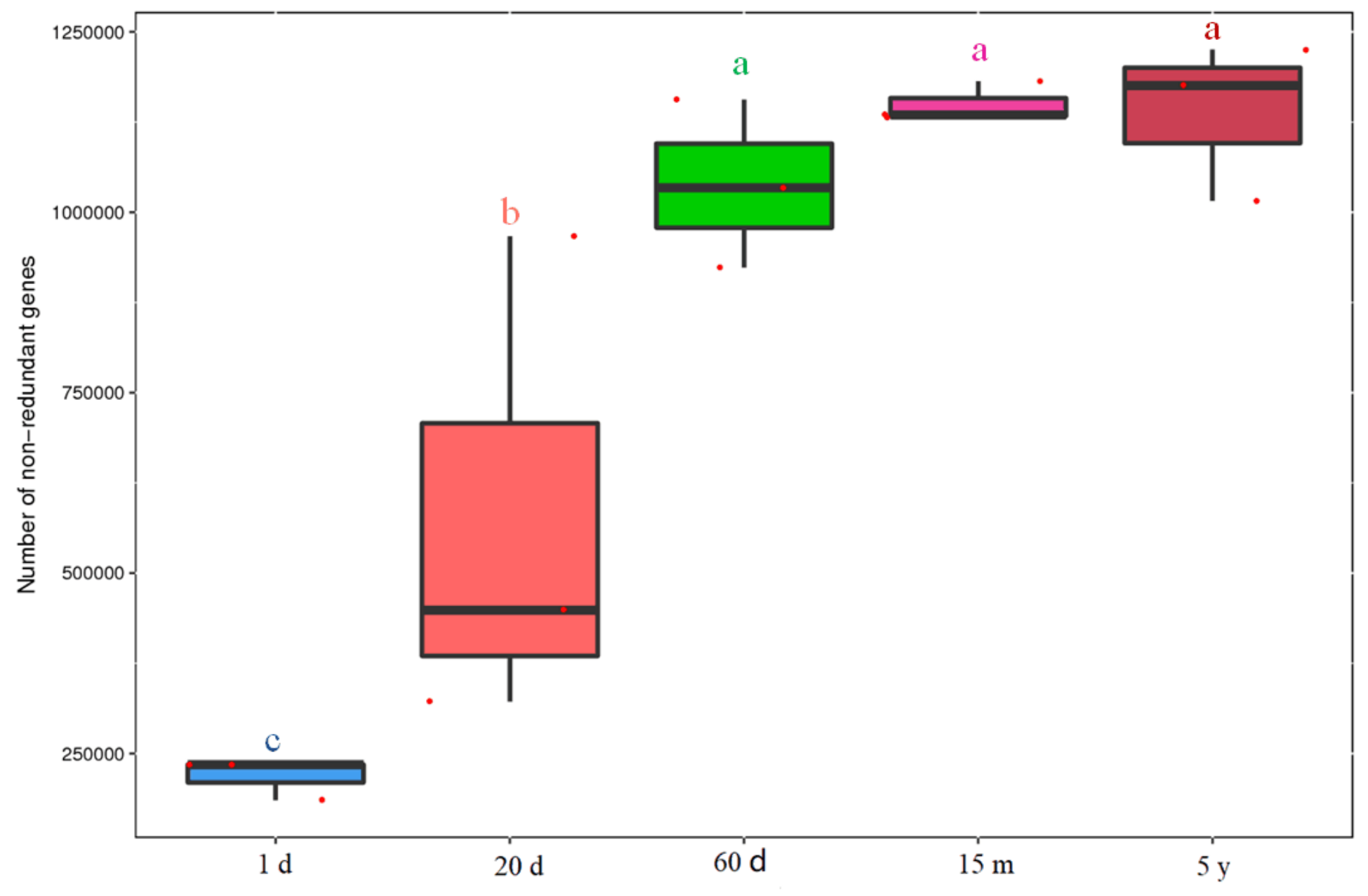

Figure 3

Box plot of gene number differences among groups.Similar shoulder labels of the same data indicate lack of statistical differ-ences $(P>0.05)$. Different lower case letters denote statistical differences $(P<$ 0.05). 

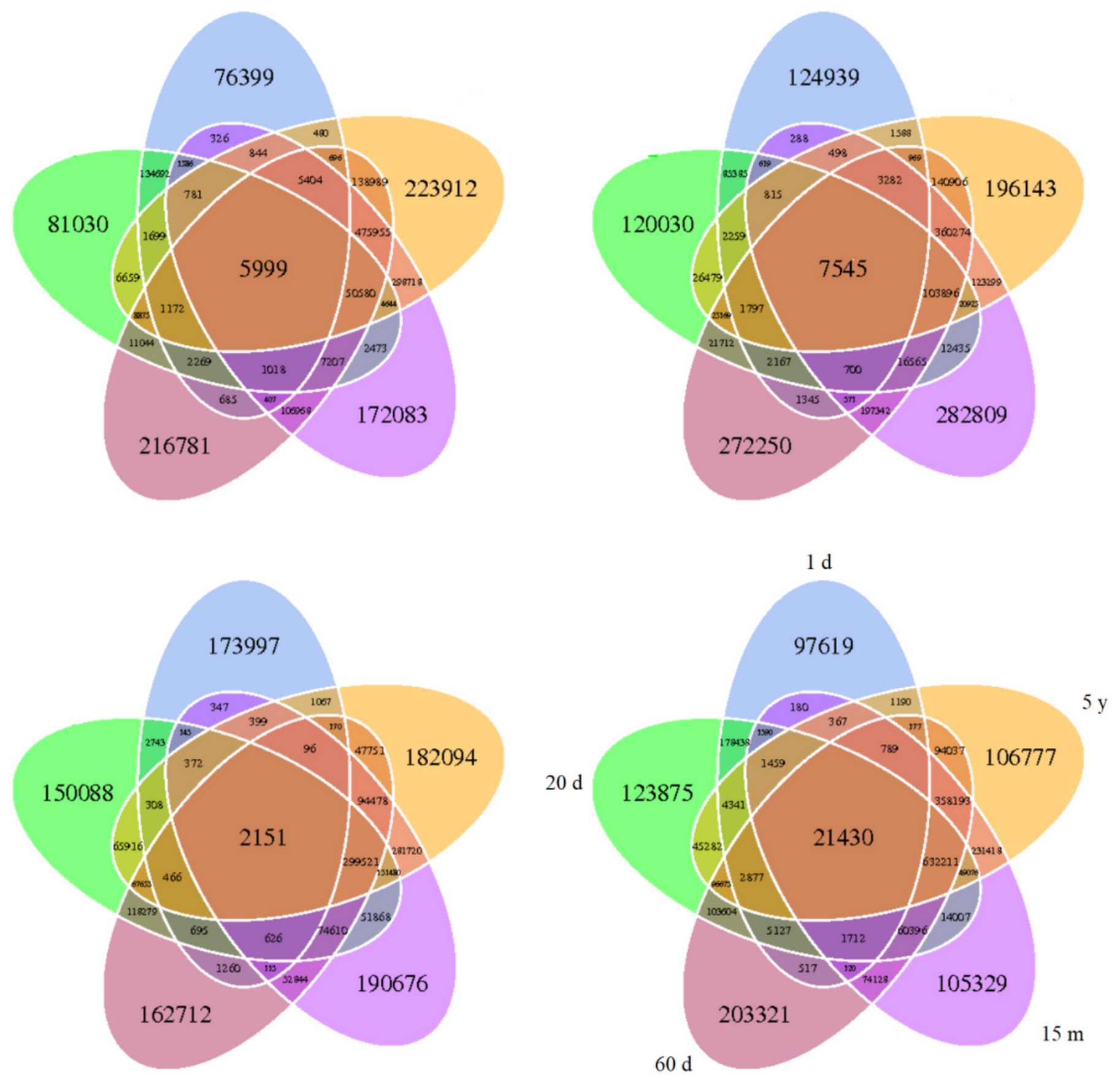

Figure 4

Venn Graph of gene numbers in the five age groups. 

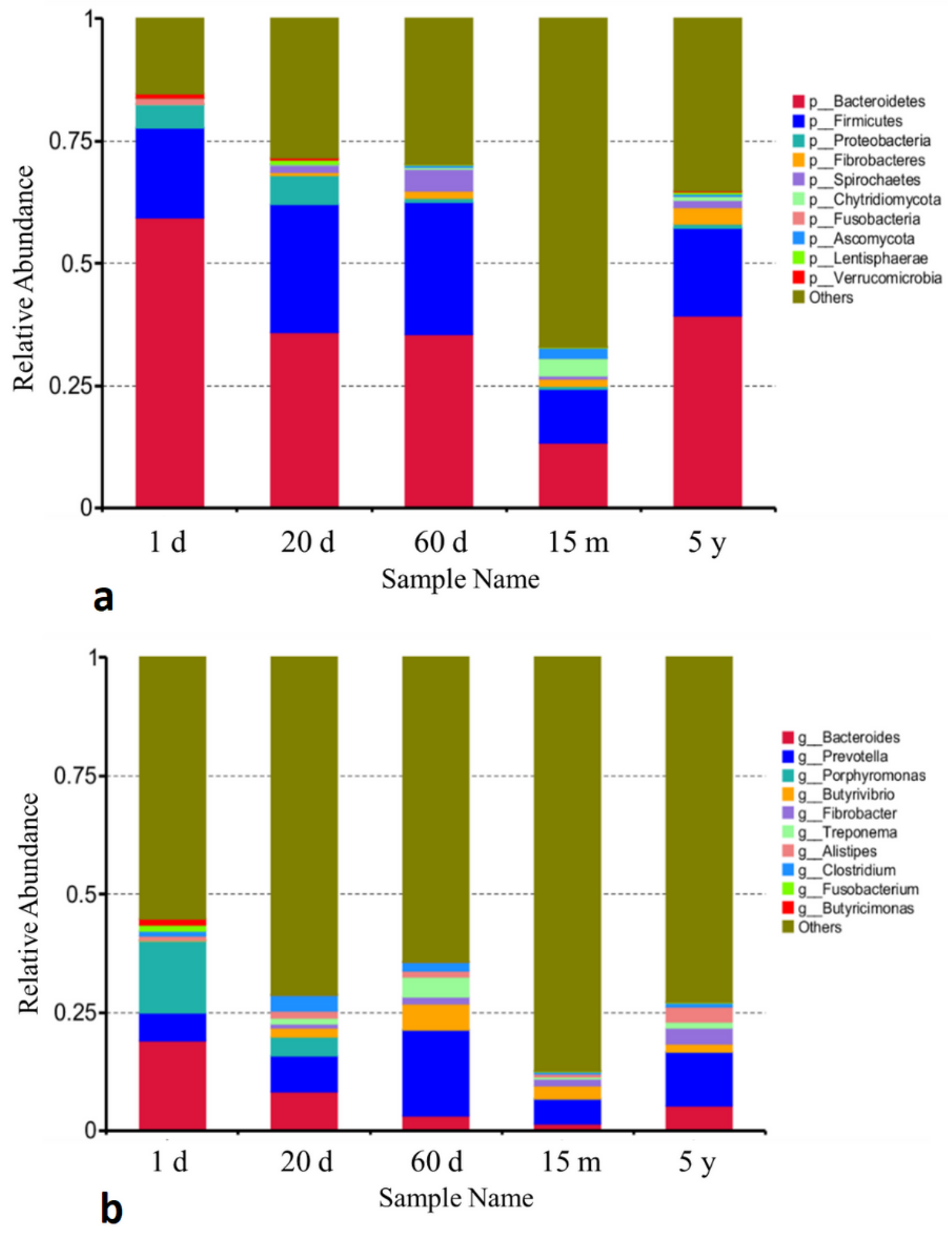

\section{Figure 5}

Relative abundance of species at phylum and genus levels. (A) Histogram of relative abundance at the phylum level (B) Histo-gram of relative abundance at the genus level. The horizontal axis represents the sample name. The vertical axis shows the rela-tive proportion of annotations to a certain type of taxa. The taxa category in line with each color block is shown in the legend. 